\title{
Análise das Reflexões de uma Professora de Ciências do Ensino Fundamental sobre Avaliação Escolar
}

\author{
PATRÍCIA DE OLIVEIRA ROSA-SILVA* \\ Programa de Pós-Graduação em Ensino de Ciências e Educação Matemática \\ Universidade Estadual de Londrina - UEL/PR \\ porsilva@hotmail.com \\ ÁLVARO LORENCINI JÚNIOR \\ Programa de Pós-Graduação em Ensino de Ciências e Educação Matemática \\ Universidade Estadual de Londrina - UEL/PR \\ alvarojr@uel.br
}

\begin{abstract}
Resumo
Este trabalho enfoca as idéias reflexivas sobre avaliação escolar de uma professora de Ciências do Ensino Fundamental no desenvolvimento de uma parceria colaborativa na escola. O processo de parceria envolveu uma estratégia de intervenção reflexiva denominada autoscopia trifásica, simulando uma "sala de espelhos" (Schön, 2000), que levou a professora a refletir nas fases pré-ativa e pós-ativa, ou seja, antes e depois da aplicação da prova com consulta aos alunos da $7^{a}$ série. Como referencial teórico, utilizamos o conceito de prática reflexiva de Donald Schön $(1997,2000)$. As reflexões da professora demonstram que a avaliação escolar é um tema do currículo que lhe permite reconsiderar ações, a fim de promover mudanças, se necessárias ou oportunas na sua prática educativa.

Palavras-chave: ensino de Ciências, formação continuada, avaliação escolar, reflexão sobre a prática.
\end{abstract}

\section{Resumen}

Este trabajo enfoca las reflexiones sobre evaluación escolar de una profesora de Ciencias de la Enseñanza Fundamental en el desarrollo de una asociación colaborativa en la escuela. El proceso consistió en una estrategia de intervención reflexiva denominada autoscopia trifásica, simulando una "sala de espejos" (Schön, 2000), que le permitió a la profesora reflexionar sobre las fases pre-activa y post-activa, o sea, antes y después de la aplicación de la prueba realizada por los alumnos de $7^{\circ}$ año en la que se permitió consultar el material didáctico. Como referencia teórica, utilizamos el concepto de práctica reflexiva de Donald Schön $(1997,2000)$. Las reflexiones de la profesora demuestran que la evaluación escolar es un tema del currículo que le permite rever sus acciones, con el fin de realizar cambios, en caso de ser necesarios u oportunos, en su práctica educativa.

Palabras-clave: enseñanza de Ciencias, formación continua, evaluación escolar, reflexión sobre la práctica.

${ }^{*}$ Bolsista do CNPq - Brasil. 


\begin{abstract}
This paper deals with a Science teacher's reflective ideas about school evaluation while developing a collaborative partnership in an Elementary school. This process involved a reflective intervention strategy called triphasic autoscopy which simulates a "hall of mirrors" (Schön, 2000) leading the teacher to reflect on the pre- and post-active phases, that is, before and after a test where $7^{\text {th }}$ grade students were allowed to refer to their books to do it. Donald Schön's reflective practice concept was used as a theoretical framework (1997; 2000). The teacher's reflections demonstrate that school evaluation is a curricular theme, which enables her to reconsider her actions in order to promote necessary or opportune changes in her educational practice.
\end{abstract}

Key words: science teaching, continuing education, school evaluation, reflection on practice. 


\section{INTRODUÇÃO}

O modelo de prática avaliativa adotado na maioria das escolas brasileiras tem deixado insatisfeitos alunos, pais, professores e o próprio sistema político-educacional, que reclamam dos altos índices de evasão, da repetência escolar e das dificuldades de aprendizagem dos alunos (Luckesi, 2002). A prática avaliativa predominante tem-se caracterizado pela aplicação de provas diversas por meio das quais os professores avaliam seus alunos, geralmente atribuindo notas, a fim de promovê-los ou não para a série ou fase seguinte. Nesse processo, os estudantes deparam-se, constantemente, com julgamentos tais como certo, errado ou incompleto e também com a incompreensão dos professores acerca das dificuldades que cometem nas provas.

Em vista disso, é consenso entre diversos pesquisadores que os professores devem estar em constante processo de formação durante o exercício da sua função para refletir sobre os problemas da prática no intuito de solucioná-los (Alarcão, 2003; Elliot, 1998; Imbernón, 2001; Zeichner, 1992). A avaliação relacionada diretamente à formação docente é um meio de auxiliar os professores a melhorar o seu ensino (Day, 1993) e de ajudá-los a refletir sobre "a suposta objetividade das avaliações, bem como seu uso quase exclusivo para julgar os alunos" (Hoyat, 1962 apud Carvalho, Gil-Pérez, 2001, p. 28).

Contudo, refletir sobre a prática pedagógica não é tarefa fácil (Dewey, 1979), nem a formação continuada do professor é algo espontâneo, que se dê pelo simples fato de o profissional estar na escola. É necessário, por parte do trabalho de pesquisa e/ou gestão escolar, explorar momentos que favoreçam processos de intervenção reflexiva da prática pedagógica com a intenção de ajudar os professores a identificar os problemas para resolvê-los (Candau, 1997).

Partindo dessa perspectiva, este estudo, de cunho qualitativo (Bogdan, Biklen, 1994), em que os dados se revelam ao investigador, toma como referência a prática avaliativa de uma professora de Ciências do Ensino Fundamental para investigar as seguintes questões: que reflexões sobre avaliação foram feitas pela professora, decorrentes de uma estratégia de intervenção nas horas/atividade ${ }^{1}$ na escola? Quais as implicações dessas reflexões na prática avaliativa?

1 A hora/atividade, período em que o professor desempenha funções relacionadas com a docência, que compreende preparação das aulas, processo de avaliação dos alunos, discussões pedagógicas, atendimento à comunidade escolar, atividades de estudo e outras correlatas, será cumprida, integralmente, no mesmo local de exercício e no mesmo turno das horas/aula (Resolução n. 10/2003, Art. 25, § 1', Secretaria de Estado da Educação do Paraná - SEED/PR). 
Em linhas gerais este trabalho objetiva:

- identificar um tipo de prova elaborado pela professora de Ciências na sua ação docente;

- caracterizar a tendência pedagógica subjacente ao conhecimento na ação da professora, de acordo com as epistemologias do trabalho docente propostas por Becker (1998);

professora.

- analisar as implicações das reflexões na prática avaliativa da

O trabalho está estruturado em quatro partes. Na primeira abordamos o referencial teórico sobre o conceito de prática reflexiva, baseando-nos, principalmente, nas idéias de Schön $(1997,2000)$. Na segunda seção descrevemos a metodologia da pesquisa. Na terceira apresentamos e analisamos os dados, assim como um quadro-síntese dos temas reflexivos sobre a prática avaliativa e, na última parte, tecemos algumas considerações.

\section{FUNDAMENTAÇÃO TEÓRICA}

A formação continuada de professores na dimensionalidade reflexiva tornou-se uma constante, a partir da década de 1980, com o conceito de prática reflexiva de Donald Schön. Este autor afirma que à medida que os profissionais entram em contato com seu trabalho e se familiarizam com ele, distanciam-se da reflexão na e sobre a ação. Desse modo, a ação docente de avaliar os alunos, por exemplo, pode transformarse em processo rotineiro e espontâneo, pois quando o professor está apto a realizar determinadas tarefas é comum que as execute em seqüências fáceis e não pare para pensar a respeito delas, nem faça reflexões sobre sua ação.

Assim, Schön defende a formação docente baseada em uma epistemologia da prática, na qual o professor pode lançar mão da sua experiência profissional, valorizando-a no seu contexto social, por meio da reflexão e do conhecimento tácito (Schön, 2000).

Ao referir-se à reflexão, o autor sustenta o conceito de reflexão de Dewey (1979, p. 13): "espécie de pensamento que consiste em examinar mentalmente o assunto e dar-lhe consideração séria e consecutiva". Para Dewey, consecutividade significa seqüência de pensamentos concentrados em um objeto de análise, com flexibilidade, variedade e mudanças de posições de idéias, mas sem se desviar do objetivo a alcançar.

O conhecimento tácito é o conhecimento na ação, prático, interiorizado e implícito, que o profissional adquire em um conjunto de 
hábitos cotidianos, tornando-o rotina (Polanyi, 1967 apud Schön, 2000). Pacheco (1995) aborda sobre esse conhecimento nos seguintes termos:

O que os professores sabem define-se como um corpo de significados, conscientes ou inconscientes, que surgem a partir da experiência e que se expressam em acções pessoais. É um conhecimento intimo, social e tradicional que se orienta mais para a acção e se contextualiza pela profissão. (p. 55)

Partindo dessa abordagem, é possível caracterizar perfis de saberes docentes, segundo Becker (1998). Esse autor utiliza os termos "epistemologia subjacente ao trabalho docente" em vez de conhecimento na ação. A nosso ver, essas expressões têm significados que se aproximam muito, pois se referem ao saber implícito realmente utilizado pelo professor ao desempenhar a sua função na escola (Tardif, 2002). Assim, neste estudo, em diversas ocasiões, utilizamos a expressão "epistemologia subjacente ao conhecimento na ação".

Becker (1998) descreve três tipos de epistemologias do trabalho docente. Essas epistemologias revelam como os professores concebem o ensino por meio das ações e representações que expressam a respeito de como os alunos elaboram o conhecimento, matéria-prima do processo de ensino e aprendizagem. São elas: empirista, inatista ou apriorista e construtivista.

- Epistemologia empirista: o professor que pensa e age de acordo com essa tendência pedagógica concebe o conhecimento como algo que emana do meio físico ou social do objeto; logo, o aluno, sujeito ativo, passa a exercer um papel passivo em sala de aula, porque na crença empirista docente o conhecimento do estudante será determinado pelo mundo que cerca o objeto de estudo.

- Epistemologia inatista ou apriorista: o professor que apresenta essa tendência concebe que a possibilidade de aprendizagem é inata, isto é, está na hereditariedade do aluno. Para este professor, a criança já nasce pré-determinada a aprender ou aprenderá a partir dos seus estágios de maturação, ou seja, o inatismo ou o apriorismo são condições de possibilidade de gênese do conhecimento.

- Epistemologia construtivista: o professor que expressa essa tendência reconhece que o aluno é essencialmente ativo. O seu repertório de conhecimento na ação exprime um saber fazer apoiado em teorias construtivistas, cuja ênfase está em possibilitar que o aluno interaja com o objeto a ser estudado para construir o conhecimento com significado. 
Schön (2000) alerta que o conhecimento que muitos profissionais constroem é, porém, insuficiente para solucionar os problemas advindos da prática. Nesse sentido, é preciso que o professor observe atentamente a sua sala de aula, que é heterogênea, conflituosa e incerta, e mobilize o seu conhecimento na ação por meio da reflexão sobre a sua prática.

$\mathrm{O}$ autor defende três processos reflexivos no ensino que podem auxiliar o professor na sua atividade: a reflexão-na-ação, a reflexão sobre a ação e a reflexão sobre a reflexão-na-ação.

A reflexão-na-ação é o processo pelo qual o professor pensa sobre algo que lhe chama a atenção, durante a ação em aula, guiando-se na intervenção que fará na situação para ressignificar o que está realizando, enquanto ainda o realiza. No calor da ação, o professor apresenta respostas espontâneas e rotineiras que revelam um processo de conhecer-na-ação que pode ser descrito em termos de estratégias, compreensão de fenômenos e formas de conceber uma tarefa ou problema adequado à situação (Schön, 2000, p. 33).

A reflexão sobre a ação é um processo que não tem qualquer relação com a ação presente, e o professor a reconstrói mentalmente, tendo por objetivo analisá-la retrospectivamente de modo que descobrisse como o seu conhecimento na ação pode ter contribuído para um ensino satisfatório ou não.

Já o processo de reflexão sobre a reflexão-na-ação requer que o professor pense no que aconteceu, no que observou, no significado que lhe deu e na eventual adoção de outros sentidos. Refletir sobre a reflexão-na-ação é uma ação, uma observação e uma descrição, que exige o uso de palavras (Schön, 1997, p. 83). O professor, após ter descrito e construído o cenário da sua investigação, apoiado no seu conhecimento na ação criará uma problematização contextualizada, realizará uma análise e uma avaliação do seu saber fazer.

A reflexão sobre a reflexão-na-ação auxilia o profissional a determinar as ações futuras e a compreender os problemas para solucioná-los (Alarcão, 2000). Os esquemas de pensamento criados por esse movimento reflexivo podem embasar o que Alarcão (2003) acrescenta de reflexão para a ação. Esse processo é definido como aquele que envolve as reflexões consideradas argumentos e concepções que o professor se embasa para sistematizar as atividades de ensino, as quais serão desenvolvidas em sala de aula.

$\mathrm{Na}$ perspectiva da formação reflexiva, quanto mais a reflexão sobre a prática estiver voltada para a realidade em que o professor vive e para os problemas que enfrenta, mais a sua atividade estará contextualizada (Zeichner, 1992). 


\section{METODOLOGIA DA PESQUISA}

A investigação ocorreu em uma escola pública localizada na periferia do município de Londrina/PR com uma professora formada em Biologia, com 20 anos de magistério e efetivada na disciplina de Ciências, de $5^{\mathrm{a}}$ a $8^{\mathrm{a}}$ série, com 40 horas semanais.

Com base na concepção de Elliot (1998) que considera o pesquisador como promotor do desenvolvimento do professor em uma perspectiva discursiva e reflexiva da sua própria prática, estabelecemos um relacionamento de parceria colaborativa com a professora (Boavida, Ponte, 2002), dispondo de quatro horas/atividade semanais no ano letivo de 2006, acompanhando-a em suas atividades pedagógicas para registrar e investigar as reflexões acerca do seu trabalho.

Nas horas/atividade do primeiro bimestre letivo, a professora relatou-nos que nas suas aulas ocorriam procedimentos embaraçosos e conflituosos dos alunos que não permitiam o desenvolvimento das aulas que a deixavam apreensiva. Nesse sentido, o processo de consolidação da parceria baseou-se fundamentalmente em assessorar a professora nas suas dificuldades pedagógicas por meio de ações que nos levassem a uma reflexão conjunta dos assuntos da prática educativa. Para isso, foi necessário conhecer a docente em reais situações de ensino e aprendizagem em sala de aula. Então, propusemos uma estratégia de intervenção reflexiva denominada autoscopia, que possibilitou colocar a professora diante de uma "sala de espelhos" para que refletisse sobre a ação, tendo como referência a sua própria prática.

$\mathrm{Na}$ "sala de espelhos", proposta por Schön (2000), há paralelismo entre a prática de formação docente e o ensino prático de sala de aula, de modo que ocorrem situações homólogas, nas quais os pesquisadoresformadores apóiam-se para auxiliar os professores a problematizarem o seu trabalho pedagógico, por meio da demonstração de práticas educativas iguais ou semelhantes às suas.

Segundo Sadalla e Larocca (2004), autoscopia significa videogravação de uma prática, que visa à observação, análise e autoavaliação pelo protagonista dessa prática. As cenas videogravadas são submetidas às sessões de análise após o desenvolvimento da ação, as quais se destinam à apreensão do processo reflexivo do profissional em foco, por meio de suas falas. O vídeo tem a função de um espelho em que a pessoa se contempla, porém sem se olhar nos olhos (Ferrés, 1996).

A professora concordou em gravar as aulas em vídeo de acordo com as séries/turmas selecionadas por ela $\left(7^{\mathrm{a}} \mathrm{B}\right.$ e $\left.5^{\mathrm{a}} \mathrm{C}\right)$ e na ocasião em que se sentisse preparada didaticamente para ministrá-las: Eu não planejo. O meu 
planejamento do ano passado é o mesmo do ano anterior. E também estava com medo de fazer alguma besteira em sala. Assim, optamos pela autoscopia trifásica, dividindo-a em três fases da ação docente propostas por Jackson (1968 apud Saint-Onge, 2001) como pré-ativa, interativa e pós-ativa, e adaptando-a de acordo com o contexto da pesquisa:

a) Na fase pré-ativa, a professora foi estimulada a preparar as suas atividades de ensino em que ocorreram reflexões para a ação, cujo fim foi conhecer idéias acerca da sua prática educativa. Pertencem a essa fase as reflexões que a professora fez sobre a sua prática avaliativa, deixando transparecer aspectos que mais a preocuparam tais como: o que faria em sala, de que modo, com quais objetivos e expectativas. As análises e discussões apresentam-se entrecortadas pelos diálogos entre a pesquisadora e a professora e pelo registro da prova indicado nas molduras. Nessa sessão de discussão, que foi gravada em áudio, utilizamos um roteiro norteador.

b) Na fase interativa, filmamos a aula da professora. Procuramos gravar cenas que tiveram como foco central a ação docente, a interação entre a professora e os alunos e algumas ações discentes. A aula videogravada foi transcrita na íntegra, analisada e selecionadas cenas que enfatizavam o critério de confronto do que tínhamos discutido na fase préativa para a sessão de discussão na fase seguinte.

c) Na fase pós-ativa, realizamos uma sessão de discussão a respeito de determinadas cenas da sala de aula. Ressaltamos o movimento de reflexão sobre a ação proposto por um roteiro norteador de questões provocadoras do discurso reflexivo que foi gravado em áudio. As idéias reflexivas emergiram do confronto com as reflexões e ações realizadas pela professora nas fases pré-ativa e interativa. As análises e discussões apresentam-se entrecortadas pelas cenas da sala de aula, que estão nas molduras, e pelo discurso reflexivo da professora e da pesquisadora.

No período da pesquisa foram realizadas oito autoscopias. Dessas oito, apenas uma referiu-se à avaliação: uma prova com consulta, com quatro questões sobre "Organelas Citoplasmáticas e Tecidos", destinada aos alunos da $7^{\mathrm{a}}$ série B. A prova foi aplicada no mesmo dia da sua elaboração e a sessão de discussão foi realizada nove dias depois. Essa atividade de ensino foi o recorte que consideramos para este estudo.

Como síntese, apresentamos um quadro com alguns temas reflexivos da prática avaliativa da professora de Ciências. A definição dos temas foi feita com base no conteúdo das reflexões mais significativas da professora tomadas como referência na fase pré-ativa. Para caracterizar a fase pós-ativa, partimos das reflexões que serviram de confronto às idéias 
centrais já analisadas na fase pré-ativa, a fim de identificar as relações das reflexões entre as duas fases.

\section{Primeiro momento: fase pré-ativa em que se enfoca a reflexão para a ação na preparação da prova com consulta sobre Organelas Citoplasmáticas $e$ Tecidos aos alunos da $7^{\mathrm{a}}$ série $\mathrm{B}$}

Esta fase da autoscopia foi realizada em uma hora/atividade anterior à aplicação da avaliação dos alunos e foca as reflexões da professora na preparação da prova com consulta.

Professora: [Hoje] vai ter avaliação. Quem trouxer o trabalho vai fazer e quem não trouxer vai fazer avaliação também, porque pode usar o livro e o caderno. E cada um com o seu material. Só que quem não fez o trabalho vai ficar com menos vinte [pontos]. Ah! Eu não vou esquentar a minha cabeça não!

Nesse fragmento, a professora estabelece os seus critérios para a atribuição de pontos. O aluno poderá utilizar o livro e o caderno para realizar a prova. Quem não trouxer o trabalho perderá os vinte pontos previstos. A professora demonstra aparente indiferença em relação ao que ela imagina ocorrer em sala de aula: Ah! Eu não vou esquentar a minha cabeça não!, ou seja, parece que ela não pretende saber as razões por que o aluno não faz o trabalho.

Professora: Você não vai reparar se eu ficar nervosa porque em dia de prova, de trabalho, eu fico altamente estressada.

Pesquisadora: Por quê?

Professora: Eu fico assim: angustiada... Sabe quando você não quer que o aluno se prejudique porque é uma prova na qual ele pode consultar, que ele fez um trabalho. Você vai ver... Ainda mais que é segunda-feira, eles esquecem de fazer, eles não trazem [o material]. [...] eu conheço os alunos do colégio. [...]

Podemos notar que a professora sente certo desconforto em dia de prova, talvez em decorrência da preocupação com o resultado da avaliação. Ela se preocupa, receosa de que os alunos possam ser prejudicados na prova, mesmo sendo uma avaliação com consulta ao caderno, ao livro ou ao trabalho. Entretanto, os alunos geralmente não fazem as tarefas de casa nos fins de semana; no caso, o referido trabalho. Assim, a segunda-feira, dia da semana estabelecido para realizar a avaliação influencia, sobremaneira, no estado de ânimo da professora, deixando-a angustiada, pois ela sabe, por experiência, que os alunos não cumprem satisfatoriamente suas tarefas e, assim, prejudicam seu próprio desempenho na avaliação. 
Pesquisadora: Com quem você aprendeu a fazer prova assim?

Professora: Com a minha professora de estágio [na faculdade].

Pesquisadora: E quais foram as orientações que ela passou pra você??

Professora: Eram muitas orientações. Ela deixava livre pra gente fazer, depois ela corrigia. A única coisa que ela falava: procure uma prova bem diversificada, onde você vai oportunizar aquele aluno que tem facilidade visual, tem aquele outro que tem facilidade na escrita e tem aqueles que têm facilidade na memorização. E isso eu gravei. A vida inteira eu utilizei essa técnica.

Pesquisadora: Esta questão [abaixo] que você formulou envolve que função cognitiva, baseando-se nessa taxonomia? [Taxonomia de Bloom]

1) Identifique as organelas citoplasmáticas quanto à função:

a) respiração:

b) produção de proteínas:

c) armazenamento e eliminação de secreção:

d) digestão:

e) transporte de substâncias nutritivas:

Professora: Conhecimento só. É só conhecimento. Eu não quero aprofundar sintese, análise, nada. Eu quero que eles saibam o conhecimento disso daí é só identificar a figura [no livro] e qual é a função que ela tem.

Aqui, podemos deduzir que o modelo de avaliação desenvolvido pela professora reflete sua formação inicial, a partir do período de estágio, e vem influenciando seu modo de elaborar o instrumento de avaliação há 20 anos: A vida inteira eu utilizei essa técnica. Mesmo defendendo uma avaliação com funções cognitivas variadas em que predominariam aspectos visuais, de escrita e memorização, a professora elabora questões que exigem dos alunos apenas memorização, tida por ela como conhecimento. As demais questões da prova confirmam essa análise, como podemos verificar no quadro a seguir:

2) Identifique os tecidos quanto à função:

a) Tecido que serve para o revestimento e secreção:

b) Tecido que serve para preenchimento, sustentação, transporte e defesa:

c) Tecido que serve para condução de estímulos nervosos:

d) Tecido que possui reserva de gordura:

e) Tecido que serve para movimentação:

3) Qual a diferença entre:

a) mucosa:

b) serosa: 
Pesquisadora: Sobre a questão número dois, eu percebi que tem um quadro no livro [didático]. Você se baseou nesse quadro pra eles...

Professora: [Interrompendo]. Quem for inteligente não vai nem pensar, vai direto lá [no quadro]. E outra, na quinta-feira quando eu expliquei o trabalho tudo certinho, eu até indiquei, mas acontece que eu não sei como acontece: no mesmo momento em que você explica, eles já não entendem mais, já não percebem o que você está falando. Tem uns que ficam conversando. Então, eu falei: eu vou deixar.

Pesquisadora: Qual é o objetivo dessa avaliação?

Professora: É inteirar com o que eles têm no caderno, qual é o conteúdo que está no caderno! E outra, eu vou pôr avaliação de consulta. Valor: vinte pontos.

Nesse trecho, podemos caracterizar com clareza a epistemologia que subjaz o conhecimento na ação da professora. Subjacente à sua ação, a professora apresenta uma concepção de ensino e aprendizagem empirista em relação à elaboração do conhecimento pelos alunos (Becker, 1998). Para ela, o conhecimento é algo externo aos estudantes e a aprendizagem ocorre pela transferência de conceitos do professor para eles, assim como pela cópia de conteúdos no livro didático.

Pelas questões propostas na prova, podemos verificar que a professora considera o aspecto visual como recurso cognitivo, porque ela pede que o aluno relacione as respostas da questão com os itens do quadro do livro didático. Portanto, o pouco raciocínio exigido na pergunta implica um aluno passivo, pois nem do estudante, que a professora considera inteligente, ela exige raciocínio, apenas visualização. Logo, parece que ela deseja rapidez na resolução da questão, uma vez que o quadro do livro ajuda o aluno a estabelecer uma relação direta com a questão proposta: Quem for inteligente não vai nem pensar, vai direto lá. Esse é um dos pontoschave do empirismo: o professor concebe que o conhecimento se dá por força dos sentidos (Becker, 1998, p. 12).

$\mathrm{Na}$ aula que antecedeu a avaliação, a professora comenta sobre os assuntos que seriam contemplados na prova com consulta, e mesmo preparando e orientando os alunos para que a fizessem satisfatoriamente eles não ficaram atentos às suas explicações. Com a avaliação, ela pretende verificar se os alunos têm no caderno o conteúdo abordado, apenas isso, pois o caderno fornece-lhes as informações necessárias para preencher os espaços correspondentes da folha de prova.

Uma prova de baixa exigência cognitiva, como é o caso da que exige apenas memorização, teria a vantagem de facilitar a verificação dos erros e dos acertos dos alunos. Ocorre, porém, que os resultados de uma prova que exige simplesmente verificação das informações por si sós não permitem 
reconhecer se os alunos adquiriram conhecimentos com significados relevantes (Luckesi, 2002).

Professora: E uma questão [a de número quatro] eles vão formular daquilo que eles fizeram no trabalho.

Pesquisadora: Qual é a instrução dessa pergunta?

Professora: Eles vão poder formular a pergunta do jeito que eles quiserem, do jeito que souberem. Pode ser dificil, complexa de responder. Aí, vai valer os vinte pontos. E essa questão, dessa vez, vai valer. [...] eu vou dar meio ponto para quem fizer, só por fazer a resposta. Eu vou começar com uma só porque vai que eu prejudique... Até eles irem adquirindo o hábito de que tem que formular uma questão na prova.

De acordo com a professora, os alunos serão capazes de elaborar e responder uma questão se adquirirem o hábito. A criação desse hábito poderá ocorrer desde que ela lhes proponha exercícios de questões abertas. Como se trata de um procedimento novo, a docente receia que os alunos sejam prejudicados na nota; por isso a sua cautela em limitar o número de questões de responsabilidade deles a apenas uma. Encontramos a mesma cautela quanto ao critério de correção da questão elaborada por eles e da resposta dada; basta que o aluno a responda do jeito que souber para obter cinco décimos do total de pontos.

Pesquisadora: Façamos de conta que o aluno diga: "Ó professora, eu não sei fazer a questão número quatro".

Professora: Não? Tenta!

Pesquisadora: Como?

Professora: Faz uma perguntinha. No caderno de vocês tem tanta pergunta pronta!

Pesquisadora: Professora! Eu quero ouvir de você uma idéia.

Professora: Não vai ter isso não viu, pode ter certeza, aqui não!... Uma idéia?

Pesquisadora: Como eu começo uma pergunta, professora?

Professora: Qual é o nome do tecido "nananã"? Ou faça a relação entre as organelas. Faz de novo... Só que é diferente a questão, eles já têm no caderno deles.

Nesse excerto, a professora reforça a sua epistemologia empirista ao pensar que, se os alunos não souberem elaborar a questão quatro, a sua ação docente consistirá em orientá-lo a copiar a pergunta do caderno com a resposta correspondente. Podemos inferir que ela concebe o conhecimento como produto e que uma prova que exige repetição de conteúdos do caderno favorece a aprendizagem dos alunos. Assim, a função cognitiva expressa pela pergunta passa a ser irrelevante: Faz uma perguntinha. No caderno de vocês tem tanta pergunta pronta! Portanto, os alunos dispõem de 
outros tipos de questão no caderno, de que poderão lançar mão e se servir, em lugar das que eles poderiam elaborar. De acordo com Becker (1998), quando o conhecimento é concebido pelo professor como produto, este é tão perfeito que não pode ser questionado, reelaborado ou reconstruído com a ajuda do próprio professor ou dos outros alunos, mas tão somente reproduzido homogeneamente.

Supondo que algum aluno pudesse ter dificuldades na formulação da questão, a pesquisadora pergunta: Como eu começo uma pergunta, professora?, ao que a professora responde que se formule a pergunta recorrendo-se à simples recordação: Qual é o nome do tecido "nananã"? Ou faça a relação entre as organelas. Ela sugere que os alunos façam perguntas rotineiras. Tais perguntas, porém, não lhes favorece o desenvolvimento do raciocínio crítico. Quando os alunos têm a oportunidade de (re)elaborar uma questão recorrendo ao raciocínio, a professora volta a indicar-lhes o recurso do caderno ou do livro. Parece que a professora foge à responsabilidade de interagir com o aluno em um momento em que a aprendizagem e a avaliação poderiam estar relacionadas, isto é, "a avaliação a serviço das aprendizagens [dos alunos] o máximo possível" (Hadji, 2001, p. 15).

Pesquisadora: E se tiver alguém que pergunte assim: "Professora, eu tenho uma pergunta curiosa, mas eu não sei a resposta. Posso pôr essa pergunta?"

Professora: Pode, pode, mas só a pergunta.

Pesquisadora: Por exemplo, por que meu coração não pára de bater quando eu peço que ele pare?

Professora: Mas isso não faz parte.

Pesquisadora: Não faz parte do tecido muscular estriado cardíaco?

Professora: Isso não vai sair daqui [do colégio] não, tenho certeza!

Pesquisadora: Aí um outro pergunta assim: "Ó professora, eu posso fazer uma pergunta mais dificil?"

Professora: Pode.

Pesquisadora: Mas como? Eu não quero dar exemplo... Eu quero uma situaçãoproblema!

Professora: Dessa eu posso ter certeza, te garanto que eles não vão formular essa pergunta.

Pesquisadora: E o Wil lá na sala, hein? (Nas aulas que investigamos, observamos que o Wil é um menino participativo e questionador.)

Professora: Ah, não! Mas o Wil até certo ponto ele faz, depois ele não faz tão difícil assim. Vai dar o sinal. Eu estou nervosa.

Nesse diálogo, podemos observar que a professora não relaciona, à primeira vista, o conteúdo da prova com o tipo de questão que a pesquisadora propõe: Por exemplo, por que meu coração não pára de bater 
quando eu peço que ele pare? Mesmo porque ela pouco espera da habilidade criadora dos alunos: Isso não vai sair daqui [do colégio] não, tenho certeza!; ela não acredita que os alunos sejam capazes de elaborar uma pergunta de função explicativa: Te garanto que eles não vão formular essa pergunta. Caso a certeza da professora quanto à incapacidade do aluno - $O$ Wil até certo ponto ele faz, depois ele não faz tão difícil assim - for revelada, implícita ou explicitamente, em sala de aula, ela poderá desperdiçar a única oportunidade de orientar os alunos a (re)criar uma pergunta e respondê-la. Temos aqui mais uma faceta do empirismo: pouca expectativa da professora em relação à aprendizagem dos alunos.

Na literatura, a baixa expectativa do professor está relacionada à teoria da dissonância cognitiva, defendida por Noizet e Caverni (1978 apud Hadji, 2001), que diz respeito à coexistência de dois elementos cognitivos antagônicos no processo avaliativo, em que determinadas ações docentes vão contra as expectativas de aprendizagem dos estudantes e isso os impede de avançar na elaboração do conhecimento escolar.

É importante salientar que a professora inicia e termina apreensiva a preparação da prova.

\section{Segundo momento: fase pós-ativa em que se enfoca a reflexão sobre a $a c ̧ \tilde{a} o$ em confronto com a fase interativa}

Nesta fase da autoscopia apresentamos determinadas cenas gravadas da sala de aula (fase interativa) à professora e desenvolvemos, com o auxílio do vídeo, uma sessão de discussão. Essa sessão ocorreu nove dias após a aplicação da prova aos alunos e durou duas horas/atividade.

Cena 1 - Instruções sobre a prova aos alunos

Professora: É o seguinte: na semana passada eu escrevi aqui no quadro: Trabalho de Ciências - entrega dia três do quatro. E o dia três do quatro é hoje. Esse trabalho vai ser entregue após a prova porque nós vamos fazer três perguntinhas, quatro.

Eu vou entregar as folhas pra vocês e vocês poderão utilizar caderno, livro, o trabalho. Tudo bem! Quem não fez o trabalho vai fazer a prova do jeito que souber, do jeito que puder e o trabalho infelizmente vem junto com a prova.

Pesquisadora: O que você achou dessa instrução antes de aplicar a prova? Professora: Foi uma forma assim com consulta, que eles podiam estar estudando. Depois que eu fui analisar a prova, eu achei uma prova com um teor de questões dificeis pra quem não tinha feito o trabalho nem sintonizado. Mas eu acho que foi válido. Só que eu estou chegando numa conclusão: o negócio é dar uma boa aula, o 
aluno entendeu ou não entendeu e prova. Prova assim: com um texto interpretativo, bem reflexivo pro aluno ver que as coisas não são fáceis. Vou dar um texto que ele vai ter que usar a inteligência pra interpretar. Eu vou fazer isso no $2^{\circ}$ bimestre. Cheguei nessa conclusão. Um texto com desenho, ...

A professora chega à conclusão de que a prova, mesmo com questões que exigiram apenas memorização, foi difícil para os alunos que não fizeram o trabalho. Quem não fez o trabalho não contou com esse recurso para consulta, restando, portanto, o livro e as anotações do caderno. Assim, a conclusão a que ela chega - O negócio é dar uma boa aula, o aluno entendeu ou não entendeu e prova - está sustentada pela necessidade que ela sente de se dedicar mais à exposição dos conteúdos para justificar um maior conhecimento das questões nas provas: Com um texto interpretativo, bem reflexivo pro aluno ver que as coisas não são fáceis. Vou dar um texto que ele vai ter que usar a inteligência pra interpretar.

Professora: Eu pensei assim: eu queria fazer uma prova bem elaborada com um texto significativo. Fazer um questionamento de interpretar. Esses alunos não sabem ler, resolver, interpretar, resumir, não sabem tirar a sintese do texto.

Pesquisadora: Você percebe que quando você cita as funções de interpretar, resumir e sintetizar, você está num outro nível da taxonomia [Bloom], diferente daquele sobre o qual nós conversamos? [na fase pré-ativa]

Professora: Você sabe por quê? Porque é o seguinte: eu estou vendo que os alunos conhecem... A parte conceitual, que nós ficamos muito tempo parado, o aluno já tem esse dominio. Então, nós temos que aproveitar mais coisas desse aluno. [...] Isso agora é sério! Vamos supor: no fim do bimestre, na metade desse ano que até lá eu vou estar familiarizada em formular [perguntas], eu posso dar um trabalho no qual eles formulam quatro questões? Eles vão formular?

Nas falas da professora, podemos supor que a disposição para elaborar uma prova interpretativa se deve ao fato de ela ter notado, em seus alunos, algumas necessidades educativas: Esses alunos não sabem ler, resolver, interpretar, resumir, não sabem tirar a sintese do texto. Ela passa a reconhecer que eles estão familiarizados com estratégias de ensino cuja ênfase está nos conteúdos conceituais, e que há possibilidades de ela aproveitar os conhecimentos prévios dos alunos.

Pesquisadora: Qual foi a reação deles enquanto você distribuía as folhas?

Professora: Até que eles estão calmos, porque tem turmas que são mais agitadas, ficam em pé, conversando. Eu nunca tinha me visto entregar uma folha de prova. Eu nunca tinha visto essa reação deles. Oh, a gente reclama muito, mas se a gente se organizar um pouco eles se tornam mais colaborativos! E é isso que eu queria... Que daqui pra frente as minhas aulas fossem mais organizadas, planejadas. 
Nesse trecho, a professora faz uma apreciação da conduta dos alunos e percebe que suas reações correspondem à maneira como ela lida com eles, o que a leva a estabelecer uma relação entre as aulas planejadas, bem conduzidas em sala, com a tendência de os alunos tornarem-se mais colaboradores, isto é, menos indisciplinados.

\section{Cena 2 - Tendência da professora em orientar a resolução da prova}

Professora: É o seguinte: eu vou dar uma explicadinha. Aqui vocês vão apenas identificar conforme a função que já está ali, qual a organela citoplasmática, na primeira questão:

1) Identifique as organelas citoplasmáticas quanto à função:

a) respiração:

b) produção de proteínas:

c) armazenamento e eliminação de secreção:

d) digestão:

e) transporte de substâncias nutritivas:

Alunos: Burburinhos.

Pesquisadora: Por que você agiu assim? Por que você explicou pra eles?

Professora: Por que eu tenho o hábito de qualquer exercício que eu vá fazer eu explico pra eles antes. Mas não sei se está certo isso.

Pesquisadora: No momento em que você estava explicando você estava pensando no quê?

Professora: Em explicar realmente pra eles. Mas teve aluno que você viu: o Leo não parou de conversar nem na explicação. Então, isso é que me irrita. Agora eu não podia ficar irritada, ou toda a prova que eu for dar eu vou ficar irritada com essa questão da conversa! Como que a gente faz?

Podemos perceber que a professora tem o hábito de explicar as questões da prova, mesmo quando permite consulta a diversas fontes. Isso parece indicar a sua preocupação com os alunos no sentido de impedir que tenham um baixo desempenho nas avaliações.

Ao descrever a cena, a professora nota que a sua irritabilidade a incomoda e passa a refletir sobre essa problemática com um questionamento, para ela, no mínimo, pertinente: [...] ou toda a prova que eu for dar eu vou ficar irritada com essa questão da conversa! Como que a gente faz? 
Cena 3 - Interação entre professora e alunos

Alunos: Burburinho baixo.

Professora: Ô mocinho! Só vou dizer uma coisa: assim que eu terminar [de expor a prova na lousa], já é pra estar respondida também!

Aluno: Ô louco!

Professora: Com certeza!

Aluno: É pra copiar e responder!

Professora: Será que eu preciso continuar falando assim? De repente, o aluno não gosta de ser chamado atenção publicamente...

A dúvida da professora - Será que eu preciso continuar falando assim?, parece mostrar-nos que ela reconhece que não deveria ter tido a atitude de advertir os alunos, em público. Ela percebe a sua inflexibilidade ao se relacionar com os estudantes, na ocasião da prova, e isso também não lhe agrada, porque se trata de um momento no qual há a necessidade de o professor interagir com os alunos em um clima de tranqüilidade.

Cena 4 - Instrução da questão número quatro - questão aberta

Professora: E a quarta questão não está ali porque cada aluno vai formular a questão que gostaria que aparecesse na prova e não apareceu. Quando eu fiz a primeira prova eu fiz um treino. Agora, ela vai fazer parte da avaliação. Então, a quarta questão eu até ia por aqui [na lousa]: o aluno vai formular. Então, eu vou deixar em branco. Vocês é que vão, por exemplo, formular questão de desenhar, de relacionar, vocês que vão fazer.

Aluno: Tem que fazer e responder?

Professora: Fazer e responder. Formular a questão e responder.

Hug: Posso fazer... Por que a gente tem que respirar?

Professora: Tem que ser uma pergunta que faça parte de organelas e tecidos. Que faça parte desses dois conteúdos. [Tom reticente]

Wel: Ah, não! O que é tecido?

Professora: Ele [o Hug] é um dos que mais captam as coisas e não é de fazer nada. E eu tinha uma concepção errada desse menino. Ele foi o meu aluno na $5^{a}$, na $6^{a}$, repetiu a $6^{a}$; fez a $7^{a}$ e repetiu. Eu tinha uma concepção errada, porque ele era muito faltoso, muito relapso, não queria nada com nada. Esse ano, ele está organizado e eu não sei o que aconteceu. Ele já era aluno repetente com muito problema, um fracasso escolar propriamente dito, e eu fiquei assim: chocada, porque a partir desse momento [de reflexão] a gente vai ter que ter outra postura para avaliar os alunos e analisar. É aí que a escola peca.

Pesquisadora: Qual é o pecado?

Professora: O pecado da avaliação, da reprova. Muitas vezes, esse menino não tinha sido estimado nunca. 
Podemos inferir que o fato de a professora pouco esperar dos alunos que são um fracasso escolar propriamente dito, na área do conhecimento, influencia no nível de exigência cognitiva das provas. A participação do Hug, aluno repetente, faltoso e também considerado relapso, desperta a atenção da professora; ela passa a refletir que uma prova como a que foi aplicada não conseguiria avaliar a contento as capacidades cognitivas dos estudantes. Portanto, refazer para melhor a imagem que ela tem dos alunos implica "prestar mais atenção" nos diversos tipos de habilidades que eles têm, para proporcionar formas de avaliação mais ajustadas para satisfazer a aprendizagem deles.

Pesquisadora: Nós pensamos numa situação assim quando nós estávamos preparando essa prova. Eu perguntei pra você: e se o aluno, no momento, fizer uma pergunta com uma outra função cognitiva? [diferente da memorização] Você se lembra?

Professora: Eu lembro. Inclusive, o Hug me perguntou: Por que nós respiramos? Aí é um outro contexto. Outro... Mas está voltado para o corpo, né?

Pesquisadora: E para as mitocôndrias: para a respiração celular aeróbia.

Professora: Só que eu também pequei: lembra que na hora em que ele fez a pergunta eu cortei falando assim: tem que estar voltada para as organelas e para os tecidos. De repente, ele pode fazer as perguntas das mitocôndrias como ele pode fazer outras perguntas.

Pesquisadora: $O$ que você sentiu que cortou?

Professora: Eu cortei o raciocínio dele. Eu podia ter aproveitado, dado um gancho e ter falado: ótimo, pode ir por aí.

Pesquisadora: Você cortou com a expressão da fala?

Professora: Não. Então, eu cortei porque eu sou conteudista e eu não analisei por essa parte. Eu não fiz a conexão da organela citoplasmática na hora. Mas isso é humano, sabia? Porque a gente não pode estar sempre conectada e ligada a tudo, só se o professor tem essa facilidade de conectar.

As reflexões sobre a ação que a professora desenvolve nesse trecho são caracterizadas pelo reconhecimento de que havia perdido a oportunidade de conhecer e explorar o que o aluno poderia expressar por meio da pergunta - Por que a gente tem que respirar? -, pelo fato de não ter relacionado, naquele momento, o fenômeno da respiração pulmonar com o da respiração celular aeróbia promovido pelas mitocôndrias, assunto da unidade do livro didático utilizado como consulta na avaliação. Parece que essa reação está associada à sua pouca familiaridade em relacionar conteúdos conceituais com uma situação contextualizada. Nessas reflexões, a professora comenta que poderia ter uma conduta diferente, ou seja, a de encorajar o aluno a desenvolver a idéia. Por outro lado, reconhece as suas limitações para refletir no momento da ação a fim de atender prontamente 
as demandas educativas dos alunos: A gente não pode estar sempre conectada e ligada a tudo, só se o professor tem essa facilidade de conectar.

Pesquisadora: Por que você pensou que eles não elaborariam perguntas de alto nível cognitivo?

Professora: Sabe o que acontece: professor tradicional acha que o aluno não tem conhecimento prévio das coisas, não tem uma noção do todo, não é globalizado, nem se interage com a sociedade e [...] tem hora que a gente pensa que aluno não pensa, mas o aluno pensa. Nós não podemos mais pensar que o aluno vem pra escola burrinho e que nós vamos pôr conteúdo ali dentro pra eles, não vamos.

Nesse trecho, notamos que a professora reconhece que sua expectativa em relação ao grau de conhecimento da questão que seria formulada pelos alunos foi baixa. A razão disso está na sua conduta de professora tradicional que não leva em conta os conhecimentos prévios dos alunos. Nesse processo reflexivo, admite que seu estilo de ensino, por meio da transmissão de informações, torna os alunos passivos não lhes facultando a aprendizagem: Nós não podemos mais pensar que o aluno vem pra escola burrinho e que nós vamos pôr conteúdo ali dentro pra eles, não vamos.

Para finalizar esta segunda parte, selecionamos um trecho que apresenta uma avaliação da sessão de discussão:

Pesquisadora: Você está gostando? [da sessão de discussão com vídeo]

Professora: Eu estou. Eu senti que isso aqui rende mais porque está lidando com a minha prática. Há muitos anos que eu queria lidar com a minha prática.

Segundo a professora, a nossa interação tem revelado satisfação e rendimento positivo pelo fato de estar associada diretamente com a sua prática de sala de aula, pois era seu desejo estudar com alguém da área de Ciências na escola onde trabalha há 20 anos. 


\section{Terceiro Momento: Síntese representativa das reflexões sobre avaliação escolar da professora de Ciências}

\section{Quadro 1 - Temas reflexivos da prática avaliativa da professora de Ciências}

\begin{tabular}{|c|c|c|c|}
\hline \multirow{3}{*}{$\begin{array}{l}\text { Temas } \\
\text { reflexivos da } \\
\text { prática } \\
\text { avaliativa }\end{array}$} & \multicolumn{3}{|c|}{ Autoscopia } \\
\hline & \multicolumn{2}{|c|}{$\begin{array}{l}\text { Fase pré-ativa: reflexão para a ação } \\
\text { Característica da epistemologia da prática: } \text { empirista }\end{array}$} & \multirow{2}{*}{$\begin{array}{c}\text { Fase pós-ativa: reflexão sobre } \\
\text { a ação } \\
\text { Processo de conscientização } \\
\text { Citação das reflexões }\end{array}$} \\
\hline & Idéias centrais & Citação das reflexões & \\
\hline $\begin{array}{l}\text { Avaliação na } \\
\text { dimensão } \\
\text { emocional }\end{array}$ & Desconforto & $\begin{array}{l}\text { Você não vai reparar se eu ficar nervosa } \\
\text { porque em dia de prova, de trabalho, eu } \\
\text { fico altamente estressada. }\end{array}$ & $\begin{array}{l}\text { Agora eu não podia ficar irritada ou } \\
\text { toda a prova que eu for dar eu vou } \\
\text { ficar irritada com essa questão da } \\
\text { conversa! }\end{array}$ \\
\hline $\begin{array}{l}\text { Avaliação na } \\
\text { dimensão } \\
\text { cognitiva }\end{array}$ & $\begin{array}{l}\text { Conhecimento } \\
\text { como produto }\end{array}$ & $\begin{array}{l}\hat{E} \text { só conhecimento. Eu não quero } \\
\text { aprofundar síntese, análise, nada. Eu } \\
\text { quero que eles saibam o conhecimento } \\
\text { disso daí: é só identificar a figura [no } \\
\text { livro] e qual é a função que ela tem. }\end{array}$ & $\begin{array}{l}\text { Prova assim: com um texto } \\
\text { interpretativo, bem reflexivo pro } \\
\text { aluno ver que as coisas não são } \\
\text { fáceis. } \\
\text { Vou dar um texto que ele vai ter que } \\
\text { usar a inteligência pra interpretar. }\end{array}$ \\
\hline $\begin{array}{l}\text { Aprendizagem } \\
\text { dos alunos no } \\
\text { processo } \\
\text { avaliativo }\end{array}$ & $\begin{array}{c}\text { Cópia e } \\
\text { memorização } \\
\text { dos conteúdos }\end{array}$ & $\begin{array}{l}\text { É inteirar com o que eles têm no caderno, } \\
\text { qual é o conteúdo que está no caderno. } \\
\text { Faz uma perguntinha. No caderno de } \\
\text { vocês tem tanta pergunta pronta! }\end{array}$ & $\begin{array}{l}\text { Nós não podemos mais pensar que o } \\
\text { aluno vem pra escola burrinho e que } \\
\text { nós vamos pôr conteúdo ali dentro } \\
\text { pra eles, não vamos. } \\
\text { Então, nós temos que aproveitar } \\
\text { mais coisas desse aluno. }\end{array}$ \\
\hline Papel dos alunos & Passivo & $\begin{array}{l}\text { Quem for inteligente não vai nem pensar, } \\
\text { vai direto lá. E, outra, na quinta-feira } \\
\text { quando eu expliquei o trabalho tudo } \\
\text { certinho eu até indiquei [o quadro no } \\
\text { livro]. }\end{array}$ & $\begin{array}{l}\text { [...] se a gente se organizar um } \\
\text { pouco, eles se tornam mais } \\
\text { colaborativos! } \\
\text { [...] a partir desse momento [de } \\
\text { reflexão] a gente vai ter que ter } \\
\text { outra postura para avaliar os alunos } \\
\text { e analisar. }\end{array}$ \\
\hline $\begin{array}{c}\text { Adoção de } \\
\text { questão aberta na } \\
\text { prova }\end{array}$ & Cautela & $\begin{array}{l}\text { Eu vou começar com uma só, porque vai } \\
\text { que eu prejudique... Até eles irem } \\
\text { adquirindo o hábito de que têm que } \\
\text { formular uma questão na prova. } \\
\text { [..]. e a número quatro eu vou dar } 0,5 \text { para } \\
\text { quem fizer só por fazer a resposta. }\end{array}$ & $\begin{array}{l}\text { [...] no fim do bimestre, na metade } \\
\text { desse ano que até lá eu vou estar } \\
\text { familiarizada em formular } \\
\text { [perguntas], eu posso dar um } \\
\text { trabalho no qual eles formulam } \\
\text { quatro questões? }\end{array}$ \\
\hline $\begin{array}{l}\text { Conhecimento do } \\
\text { conteúdo a ser } \\
\text { avaliado }\end{array}$ & $\begin{array}{l}\text { Dificuldade de } \\
\text { domínio do } \\
\text { conteúdo em } \\
\text { situações } \\
\text { contextuali- } \\
\text { zadas }\end{array}$ & $\begin{array}{l}\text { Pesquisadora: Por exemplo, por que meu } \\
\text { coração não pára de bater quando eu peço } \\
\text { que ele pare? } \\
\text { Wal: Mas isso não faz parte [do } \\
\text { conteúdo: tecido muscular estriado } \\
\text { cardíaco] }\end{array}$ & $\begin{array}{l}\text { [...] o Hug me perguntou: Por que } \\
\text { nós respiramos? Ai é um outro } \\
\text { contexto. Outro... Mas está voltado } \\
\text { para o corpo, né? Então, eu cortei } \\
\text { [o raciocínio] porque eu sou } \\
\text { conteudista e eu não analisei por } \\
\text { essa parte. Eu não fiz a conexão da } \\
\text { organela citoplasmática na hora. }\end{array}$ \\
\hline $\begin{array}{l}\text { Expectativa da } \\
\text { professora em } \\
\text { relação à } \\
\text { aprendizagem } \\
\text { dos alunos }\end{array}$ & Baixa & $\begin{array}{l}\text { Dessa eu posso ter certeza, te garanto que } \\
\text { eles não vão formular essa pergunta } \\
\text { [situação-problema do tipo citado } \\
\text { acima]. }\end{array}$ & $\begin{array}{l}\text { Eu cortei o raciocínio dele. Eu podia } \\
\text { ter aproveitado, dado um gancho e } \\
\text { ter falado: ótimo, pode ir por aí.. }\end{array}$ \\
\hline
\end{tabular}


Analisando o quadro, as reflexões para a ação, na fase pré-ativa, permitem-nos identificar alguns temas da prática avaliativa da professora, de acordo com a epistemologia empirista que subjaz seu conhecimento na ação. O primeiro tema diz respeito à avaliação relacionada à dimensão emocional, em que transparece o desconforto da professora no dia da realização da prova: Você não vai reparar se eu ficar nervosa porque em dia de prova, de trabalho, eu fico altamente estressada. Na reflexão sobre a ação, a professora dá-se conta da sua conduta irascível: Agora eu não podia ficar irritada, ou toda a prova que eu for dar eu vou ficar irritada com essa questão da conversa! Nessa reflexão, ela reconhece que poderia abrandar a sua apreensão em sala de aula.

No tema reflexivo avaliação na dimensão cognitiva, o conhecimento é tido como produto. Neste tema, na fase pré-ativa, a professora não reconhece a importância de exercícios de síntese e análise na prova, enquanto na fase pós-ativa, em suas reflexões sobre a ação, ela considera que deveria aumentar o nível de dificuldade da prova, por meio de um texto interpretativo e reflexivo: Vou dar um texto que ele vai ter que usar a inteligência pra interpretar.

Já o tema sobre a aprendizagem dos alunos no processo avaliativo é concebido, pela professora, como cópia e memorização dos conteúdos, e o principal objetivo da avaliação é fazer que os alunos transcrevam as respostas das fontes de consulta para a folha da prova. Ao refletir sobre a ação, a professora admite ser necessário aproveitar os conhecimentos prévios dos alunos e percebe que a transmissão unidirecional dos conhecimentos desfavorece a aprendizagem: Nós não podemos mais pensar que o aluno vem pra escola burrinho e que nós vamos pôr conteúdo ali dentro pra eles, não vamos. Entretanto, ela não considera os alunos como centrais no processo de aprendizagem e desconhece como conciliar os interesses deles em face do currículo de Ciências para que ela possa, de fato, mobilizar, identificar e compartilhar os conhecimentos prévios dos estudantes (Zabala, 1998).

A professora ao refletir sobre as condutas dos alunos, na fase préativa, concebe-os como passivos. Na fase pós-ativa, os alunos tendem a ser considerados como colaboradores, desde que ela organize melhor as atividades de ensino e comece a pensar a respeito de uma forma mais adequada e ajustada para analisar e avaliar os alunos: [...] a partir desse momento [de reflexão] a gente vai ter que ter outra postura para avaliar os alunos e analisar.

Ao optar, na prova, por uma questão em que o aluno formule e responda sua própria pergunta, a professora demonstra ter cautela com receio de prejudicá-lo. Esse cuidado está em permitir, inicialmente, uma 
questão apenas. Na reflexão sobre a ação, a professora diz que quando estiver mais "familiarizada" com a prática avaliativa, em que se propõe ao aluno elaborar e responder sua própria questão, ela irá recomendar um trabalho com pelo menos quatro questões desse tipo.

Podemos perceber que essa cautela está intimamente associada ao tema conhecimento do conteúdo a ser avaliado. Nesse tema, a professora mostra-se desprovida do necessário conhecimento em situações contextualizadas, e reconhece, na fase pós-ativa, que impediu o aluno de elaborar sua própria questão, porque se considera uma professora "conteudista", preocupada simplesmente com as informações a serem transmitidas, prejudicando assim as relações entre os conceitos e as situações-problema que os alunos elaboram.

Quanto à baixa expectativa da professora em relação à capacidade dos alunos, ela admite que, com certeza, eles não formulariam qualquer questão com valor interpretativo. No entanto, diante do fato ocorrido em sala de aula durante a prova, a sua reflexão a respeito da ação leva-a a afirmar que poderia ter encorajado o aluno: Eu podia ter aproveitado, dado um gancho e ter falado: ótimo, pode ir por aí.

Diante do exposto, consideramos que os temas reflexivos: avaliação na dimensão cognitiva, aprendizagem dos alunos no processo avaliativo e papel dos alunos parecem implicar possibilidades de mudança na prática educativa da professora, uma vez que no conteúdo das suas reflexões, na fase pósativa, há reconsiderações das suas condutas para ações futuras.

\section{ALGUMAS CONSIDERAÇÕES}

Pela análise e discussão dos resultados, constatamos que a avaliação escolar é um tema do currículo que leva a reflexões sobre a prática educativa do professor, assim como a desdobramentos para outros temas, os quais estão relacionados num "efeito cascata" em que um implica a ocorrência do outro no processo reflexivo, de acordo com a epistemologia que subjaz o conhecimento na ação do professor.

No momento de reflexão para a ação, fase pré-ativa, foi possível caracterizar os temas reflexivos da prática avaliativa da professora de Ciências e, assim, compreender os argumentos que sustentaram as suas reflexões ao elaborar a sua prova com consulta. Diante disso, o seu perfil de professora extremamente preocupada com a indispensável memorização dos conteúdos pelos alunos requer que ela elabore uma prova com baixa exigência cognitiva. 
O momento de reflexão sobre a ação, que ocorreu por meio das discussões sobre as cenas gravadas da aula, na fase pós-ativa, possibilitou à professora reconhecer aquilo que estava refletindo na sua prática, mobilizando o seu conhecimento na ação. De acordo com Perrenoud (2002), as reflexões distantes do calor da ação têm dois focos, a saber: um foco retrospectivo em que a professora procurou analisar e criticar o que foi realizado, dizendo, por exemplo, o que não deveria ter feito: Agora eu não podia ficar irritada, ou toda a prova que eu for dar eu vou ficar irritada com essa questão da conversa! e, com base nas reflexões, aprender sobre a prática vivenciada; e um foco prospectivo, em que ela fez reconsiderações, tais como: organizar um texto interpretativo e reflexivo para o aluno desenvolver o raciocínio: Vou dar um texto que ele vai ter que usar a inteligência pra interpretar; encorajar o aluno no momento de ele elaborar e responder uma questão aberta na prova: Eu podia ter aproveitado, dado um gancho e ter falado: ótimo, pode ir por aí; e reconhecer que o aluno é capaz: Nós não podemos mais pensar que o aluno vem pra escola burrinho e que nós vamos pôr conteúdo ali dentro pra eles, não vamos. Podemos considerar que pelo fato de a professora admitir que os alunos possuem capacidade de pensamento, ela rompe com uma das partes da sua epistemologia empirista, uma vez que constata que eles pouco interagem com os conteúdos transmitidos por ela.

As reflexões da professora demonstram que a avaliação escolar lhe permite reconsiderar ações, a fim de promover mudanças, se necessárias ou oportunas, na sua prática educativa. Além disso, as idéias reflexivas da professora evidenciam como ela pensou acerca da prática, externando com sinceridade as suas emoções, receios, dúvidas, percepções, expectativas e algumas formas de (re)pensar a avaliação.

No contexto da pesquisa, entendemos que a parceria colaborativa beneficiou a formação da professora, pois a autoscopia como recurso da "sala de espelhos" auxiliou, de certo modo, na compreensão da ação docente: Eu senti que isso aqui rende mais porque está lidando com a minha prática. Esse procedimento possibilitou à professora refletir para a ação, desenvolver a ação e refletir sobre a ação realizada, ou seja, discutir sobre avaliação antes e depois da aula, aguçando a sua criticidade.

Nessa perspectiva de formação continuada, recomendamos que pesquisadores-formadores de professores e gestores de escola não meçam esforços para criar e/ou implementar procedimentos reflexivos que levem os docentes a refletirem sobre a prática. Consideramos que um outro passo nesse sentido seria o desenvolvimento do processo de reflexão sobre a reflexão sobre a ação, que consiste em entregar ao professor as reflexões feitas por ele mesmo sobre a aula, a fim de que as analise juntamente com o pesquisador/gestor, apoiando-se em referenciais teóricos que possam 
auxiliar na compreensão/superação da epistemologia que sustenta a prática. É importante salientar que essa interação exige sólida confiança e amplo amadurecimento tanto do pesquisador/gestor quanto do professor.

\section{REFERÊNCIAS BIBLIOGRÁFICAS}

ALARCÃO, I. Reflexão crítica sobre o pensamento de D. Schön e os programas de formação de professores. In: Formação reflexiva de professores: estratégias de supervisão. Porto: Porto Editora, 2000. p. 9-39.

Cortez, 2003. 102p.

BECKER, F. A Epistemologia do professor: o cotidiano na escola. 6. ed. Petrópolis, RJ: Vozes, 1998. 344p.

BOAVIDA, A. M.; PONTE, J. P. Investigação colaborativa: potencialidades e problemas. In: GTI (org). Reflectir e investigar sobre a prática profissional. Lisboa: APM, 2002. p. 43-55.

BOGDAN, R. C.; BIKLEN, S. K. Investigação qualitativa em educação. Porto: Porto Editora, 1994. 336p.

CANDAU, V. M. Formação continuada de professores: tendências atuais. In: (org.). Magistério: construção cotidiana. Petrópolis: Vozes, 1997. p. 51-68.

CARVALHO, A. M. P.; GIL-PÉREZ, D. Formação de professores de ciências: tendências e inovações. 6. ed. São Paulo: Cortez, 2001. 120p.

DAY, C. Avaliação do desenvolvimento profissional dos professores. In: ESTRELA, Albano; NÓVOA, António. Avaliações em educação: novas perspectivas. Porto: Porto Editora. 1993. 191p.

DEWEY, J. Como pensamos: como se relaciona o pensamento reflexivo com o processo educativo, uma reexposição. 4. ed. São Paulo: Nacional, 1979. 296p. 
ELLIOT, J. Recolocando a pesquisa-ação em seu lugar original e próprio. In: GERALDI, Castorina M. G.; FIORENTINI, Dario; PEREIRA, Elisabete M. A. (orgs.). Cartografias do trabalho docente. Campinas, SP: Mercado das Letras. 1998. p. 137-152.

FERRÉS, J. Vídeo e educação. Porto Alegre: Artes Médicas, 1996. 156p.

HADJI, C. A Avaliação desmistificada. Porto Alegre: ArtMed, 2001. 136p.

IMBERNÓN, F. Formação docente e profissional: formar-se para a mudança e a incerteza. 2. ed. São Paulo: Cortez, 2001. 119p.

LUCKESI, C. C. Avaliação da aprendizagem escolar. São Paulo: Cortez, 2002. 180p.

PACHECO, J. A. O Pensamento e a acção do professor. Porto: Porto Editora, 1995. 223p.

PARANÁ (Estado). Secretaria da Educação. Resolução n. 10/2003. Dá nova redação à Resolução n. 06/2003, que trata da regulamentação de distribuição de aulas. Disponível em: <http://www.diaadiaeducacao.com. $\mathrm{br} /$ portals/portal/institucional/def/pdf/def_ef_resol1003.pdf $>$. Acesso em: 12 maio 2005.

PERRENOUD, P. A Prática reflexiva no ofício do professor: profissionalização e razão pedagógica. Porto Alegre, ArtMed, 2002. 232p.

SADALLA, A. M. F. A.; LAROCCA, P. Autoscopia: um procedimento de pesquisa e de formação. Educação e Pesquisa. São Paulo, v. 30, n. 3, p. 419433, set./dez. 2004. Disponível em: <http://www. scielo.br/scielo.pdf> Acesso em: 26 mar. 2006.

SAINT-ONGE, M. O Ensino na escola: o que é, como se faz. 2. ed. São Paulo: Loyola, 2001. 252p.

SCHÖN, D. A. Formar professores como profissionais reflexivos. In: NÓVOA, António. (coord.). Os Professores e a sua formação. 3.ed. Lisboa: Dom Quixote, 1997. p. 77-91.

Educando o profissional reflexivo: um novo design para o ensino e a aprendizagem. Porto Alegre: Artes Médicas Sul, 2000. 256p. 
TARDIF, M. Saberes docentes e formação profissional. 4. ed. Petrópolis: Vozes, 2002. 325p.

ZABALA, A. A Prática educativa: como ensinar. Porto Alegre: ArtMed, 1998. 224p.

ZEICHNER, K. M. El maestro como profesional reflexivo. Cuadernos de Pedagogía. n. 220, p. 44-49, 1992.

Recebido em: maio 2007

Aprovado para publicação em: novembro 2007 